\title{
TRÁFICO DE MULHERES PARA FINS DE EXPLORAÇÃO SEXUAL: UMA ANÁLISE COMPARATIVA ENTRE MOÇAMBIQUE E BRASIL
}

Joaquim Miranda Maloa ${ }^{1}$ José Joaquim Franze ${ }^{2}$

\author{
TRAFFICKING IN WOMEN FOR SEXUAL EXPLOITATION: \\ COMPARATIVE ANALYSIS BETWEEN MOZAMBIQUE \\ AND BRAZIL
}

RESUMO: Este artigo visa através de uma sociologia de Direito, identificar os principais fatores que contribuem para a ocorrência de tráfico de mulheres para a exploração sexual, tanto em Moçambique, como no Brasil, bem como o seu tratamento legal. Para isso, foi desenvolvido uma análise comparativa, por meio de uma pesquisa bibliográfica. O resultado da pesquisa, aponta que o tráfico de mulheres para fins de exploração sexual constitui uma realidade nos dois países. Em Moçambique, as mulheres traficadas frequentemente são transferidas para África do Sul, enquanto que no Brasil são deslocadas para o continente Europeu, alegadamente, porque alguém-Ihes prometeu emprego decente, mas chegado ao destino, tornam-se escravas sexuais a favor de terceiros.

Palavras-chave: Tráfico de mulheres. Exploração sexual. Moçambique. Brasil.
ABSTRACT: This article aims through a sociology of law, to identify the main factors that contribute to the occurrence of trafficking of women for sexual exploitation in both Mozambique and Brazil, as well as their legal treatment. For this, a comparative analysis was developed, through a bibliographical research. The results of the survey indicate that the trafficking of women for purposes of sexual exploitation is a reality in both countries. In Mozambique, trafficked women are often transferred to South Africa, while in Brazil they are displaced to the European continent, allegedly because someone has promised them decent jobs, but they have reached their destination, they become sex slaves in favor of third parties.

Keywords: Trafficking of women. Sexual exploitation. Mozambique. Brazil.

\footnotetext{
${ }^{1}$ Doutorando em Sociologia (Universidade Federal do Paraná - UFPR). Mestre em Sociologia (Universidade Federal do Rio Grande do Sul - UFRGS, 2007). Mestre em Counseling (Universidade do Zimbabwe, 2012). Graduado em Ciências Policiais (Academia de Ciências Policiais - Moçambique, 2017).

2 Pesquisador Associado do Centro de Análise e Políticas da Faculdade de Letras e Ciências Sociais da Universidade Eduardo Mondlane - Moçambique (CAP/FLCS-UEM). Mestre em Sociologia (Universidade de São Paulo - USP, 2012). Bacharel em Ciências Sociais (Universidade Eduardo Mondlane - Moçambique, 2005).
} 


\section{INTRODUÇÃO}

Moçambique e Brasil que têm um forte elemento comum, embora tenham grandes diferenças institucionais, políticas e de recursos. O elemento comum é a língua. Partimos da hipótese de que nos países que subjazem as desigualdades sociais, ocorrem sistematicamente e cotidianamente a violação dos direitos fundamentais dos cidadãos, e consequentemente as mulheres tem se exposto com facilidades ao tráfico para fins de exploração sexual.

Por meio da sociologia de Direito ${ }^{3}$, objetivamos identificar os principais fatores que contribuem para a ocorrência de tráfico de mulheres para a exploração sexual, tanto em Moçambique, como no Brasil, bem como o seu tratamento legal. Para isso, foi desenvolvido uma análise comparativa, por meio de uma pesquisa bibliográfica.

Moçambique é um país unitário, localizado no sudeste do Continente Africano, banhado pelo Oceano Índico a leste e que faz fronteira com a Tanzânia ao norte; Malawi e Zâmbia a noroeste; Zimbabwe a oeste; Suazilândia e África do Sul a sudoeste. Conforme dados do Instituto Nacional de Estatística (INE, 2017) relativos aos resultados definitivos do último censo geral da população, o país é habitado por 28.861.863 de habitantes, dos quais 15.061.006 mulheres e 13.800 .857 homens, de uma faixa etária predominantemente jovem e na sua maioria desempregados.

Enquanto que Brasil é um país federativo de dimensão continental. Ao norte, faz divisão com Uruguai; a oeste com o Peru, e a leste com a ponta do Seixas, na Paraíba. A fronteira atlântica se estende desde a foz do rio Oiapoque, no Cabo Orange (AP) no Norte até Arroio Chuí (RS), no Sul. Apenas dois países sul-americanos não têm fronteiras com o país, a saber: o Chile e o Equador. As fronteiras terrestres são dos mais variados tipos, mas com predomínio das naturais (rios, lagos e serras). Conforme dados do Instituto Brasileiro de Geografia e Estatística (IBGE, 2015), a população no Brasil é de cerca de 209 milhões de habitantes, também predominantemente jovem, com uma pirâmide estreita no topo e largo na base (IBGE, 2015).

\footnotetext{
${ }^{3}$ Sociologia do Direito é, antes de tudo, o modo de ver da Sociologia a respeito do Direito (BIRKHANN, 2015).
} 
O tráfico de mulheres para fins de exploração sexual constitui uma realidade irrefutável nos dois países. Em Moçambique, as mulheres traficadas frequentemente são transferidas para África do Sul, enquanto que no Brasil são deslocadas para o continente Europeu, alegadamente porque houve promessa de um emprego decente, mas chegado ao destino, tornam-se escravas sexuais a favor de terceiros.

Para além desta introdução, mais duas partes compõem a exposição deste artigo. Na primeira parte, aponta-se como o tráfico de mulheres para fins de exploração sexual em Moçambique e no Brasil é gerida e como ela produz um tipo de exploração sexual diferencial, pautada na transnacionalização do local. Na segunda parte, mencionamos os principais instrumentos institucionais e legais de ambos países que luta contra o tráfico de mulheres para fins de exploração sexual entre Moçambique e Brasil, n o contexto nacional e internacional.

\section{A SITUAÇÃO DO TRÁFICO DE MULHERES PARA FINS DE EXPLORAÇÃO SEXUAL ENTRE MOÇAMBIQUE E BRASIL NO CONTEXTO INTERNACIONAL}

O tráfico de mulheres no contexto internacional é um processo complexo por envolver diversos indivíduos com uma forma peculiar de atuação e com uma estrutura organizada e de difícil descoberta. Normalmente caracteriza-se pelas seguintes fases: recrutamento por meio de sedução devido a sua vulnerabilidade social; solicitação do consentimento familiar como se o trabalho fosse decente, legalização dos seus documentos individuais, transporte e seu alojamento. Conforme a convenção de PalermoNações Unidas (2000) a exploração de mulheres consiste em exploração para fins de prostituição ou outras formas de exploração sexual, incluindo o trabalho forçado ou similar a escravatura.

Segundo a Convenção das Nações Unidas Contra o Crime Organizado Transnacional (Convenção de Palermo, 2000), o tráfico de pessoas consiste no recrutamento, transporte, transferência, alojamento ou acolhimento de pessoas, recorrendo à ameaça ou ao uso da força ou a outras formas de coação, ao rapto, à fraude, ao engano, ao abuso de autoridade ou de situação de vulnerabilidade ou à entrega ou aceitação de pagamentos ou benefícios para obter o consentimento de uma pessoa que tem autoridade sobre outra, para fins de 
exploração. A exploração deverá incluir, pelo menos, a exploração da prostituição de outrem ou outras formas de exploração sexual, o trabalho ou serviços forçados, a escravatura ou práticas similares à escravatura, a servidão ou a extração de órgãos.

O tráfico de mulheres para fins de exploração sexual, tem sido uma realidade do mundo contemporâneo e lança um grande desafio para as autoridades políticas e organizações civis de todos os países, devido a sua nefastidade para as vítimas e largas vantagens para os seus praticantes. Trata-se de uma realidade complexa, porque envolve uma sofisticada e modernizada rede criminosa, cuja descoberta exige um sério redobrar de esforço conjunto, desde às autoridades de manutenção da ordem pública durante a sua fiscalização, procuradoria na sua investigação, tribunais na responsabilização criminal dos envolvidos, população em geral, inclusive às próprias vítimas na denúncia de qualquer caso do gênero. Esta rede pelo alto rendimento desta atividade, transformou-se num verdadeiro crime de colarinho branco, envolvendo inclusive políticos.

Em Moçambique, vários casos reportados são inerentes às raparigas de classe popular e com um nível de escolaridade baixo. Devido a sua condição social e econômica deploráveis, os traficantes aproveitam desta sua vulnerabilidade social, através de promessa de um emprego decente em outros países, mormente na África do Sul, onde o trabalho em salões de beleza transformou-se num autêntico emprego atrativo para a maioria das mulheres moçambicanas. A mesma rede, depois de convencer as suas vítimas, tem se encarregado pelo tratamento da documentação individual (passaporte com visto de estadia no estrangeiro) necessária para a travessia na fronteira e sua manutenção no estrangeiro, seu transporte e acomodação. Trata-se de uma rede de intervenientes, desde os que encomendam aqueles que executam e os que procedem o seu transporte (MARIANO et al., 2016). Nesta rede de tráfico tão rentável, na visão desses autores, o último beneficiário desta atividade, raramente é conhecido e presume-se que sejam pessoas poderosas "peixe graúdo" com fortes poderes de amolecer o poder das autoridades policiais e judiciais em caso de descoberta por meio de poderes financeiros "corrupção".

Nas poucas condenações existentes em África, nunca foram revelados os seus verdadeiros mandantes ou beneficiários finais. O caso elucidativo é da DIANA, uma 
moçambicana condenada a pena perpétua pelo tribunal da África do Sul pelo tráfico de mulheres moçambicanas para fins de exploração sexual:

No dia 20 de julho de 2011, o tribunal de Pretoria, África do Sul, condenou uma moçambicana de nome ALDINA DOS SANTOS (DIANA), de 32 anos de idade, a uma pena de prisão perpétua, em virtude de esta ter praticado tráfico (de Moçambique para África do Sul) de 3 menores de idade para fins de exploração sexual. A juíza do caso, disse durante a leitura da sentença que os interesses da ré nunca devem se sobrepor aos das vítimas, dos Estados moçambicano e África do Sul e muito menos da organização mundial contra o tráfico de pessoas. Ainda a juíza disse que a pena perpétua aplicada a ré se deveu a falta de arrependimento pelo que fez, defendendo-se sempre que " as vítimas se mostraram dispostas a serem exploradas sexualmente, daí que as levou para África do Sul". Conforme a juíza, a ré para além de ter explorado as jovens sexualmente, obrigava-as a tomar estimulantes (drogas) para que elas aguentassem com a sobrecarga de manter relações sexuais com mais de dez (10) parceiros por dia (JORNAL VERDADE, 2011).

Este caso, é um dos que mais impacto teve em Moçambique dentre os vários que continuam no anonimato, por um lado, devido ao alto secretismo desta atividade que torna difícil a sua descoberta e por outro lado, as suas vítimas não conseguem ter a coragem de denunciar tais práticas, por temer alguma vingança trágica por parte dos criminosos, quer contra elas próprias, quer para seus familiares, tendo em conta que o sistema de administração da justiça não é eficiente e eficaz quanto a proteção das denunciantes, tanto quanto para o enfrentamento deste fenômeno criminal. A demais, na passagem pelas fronteiras tem-se notado outra fragilidade inerente ao movimento desusado de pessoas, vezes sem conta confunde-se com os migratórios regulares, sendo por isso tão difícil discernir as vítimas deste tráfico entre os diferentes movimentos migratórios, por um lado. Por outro lado, a corrupção promovida pelas autoridades fronteiriças permite a fraca fiscalização dos migrantes (UNESCO, 2006).

O tráfico é uma forma de poder paralelo que os indivíduos criminosos usam, tendo em conta a vulnerabilidade social e econômica das vítimas. Este processo consiste em controlar e explorar o esforço das vítimas, recebendo avultadas somas em dinheiro e para as vítimas recebem uma quantia irrisória e outros benefícios que não compensa o esforço por elas empreendido (MARX, 2013). Ainda outras o fazem com promessa de uma oferta de emprego decente em atividades formais e informais. Neste caso vertente, as vítimas enquanto nas mãos dos traficantes perdem por completo os seus direitos como de liberdade, ficando na total dependência dos traficantes (MONTEIRO; OSORIO, 2009). 
O tráfico de mulheres para fins de exploração sexual em Moçambique e em Angola por exemplo, tem sido motivado pela ganância de uma vida de luxo de forma rápida por parte da rede de tráfico, por um lado. Por outro lado, a pobreza das vítimas leva nas a serem mais propensas a aceitar qualquer proposta de emprego, não raras vezes em que as vítimas por si só se envolvemem exploração sexual por consentimento próprio como fonte de sobrevivência.

Um outro caso que mais fez se sentir em África, foi do político e empresário angolano e um promotor de espetáculo, despoletado pelos órgãos de comunicação social, no qual são acusados de tráfico de mulheres brasileiras na cumplicidade de alguns brasileiros. Para Jornal Voa (2013), a Polícia Federal brasileira em São Paulo, o esquema de exploração sexual de mulheres era comandado pelo político e empresário angolano e um promotor de espetáculo em Angola. A quadrilha, segundo a fonte, traficava mulheres brasileiras para Angola, Portugal, África do Sul e Áustria, afim de prostituir, movimentando desta feita, valores monetários estimados em 45 milhões de dólares norte-americanos por ano.

Estes casos pela sua complexidade na investigação, o seu desfecho tem sido caraterizado por uma morosidade e muitas vezes caracteriza se pela impunidade dos seus autores pela falta da necessária colaboração das vítimas, por elas acharem uma via legar para a sua sobrevivência, ignorando totalmente a lei e arriscando se a vida. Por outro lado, pela falta de provas evidentes, uma vez que ninguém se prontifica a apresentar provas indiciárias do fato.

Em muitas cidades do mundo, em especial, cidades moçambicanas, angolanas, sul africanas e brasileiras, o tráfico de mulheres para fins de exploração sexual tem ocorrido também a nível interno, em prostíbulos e em bares, em que um determinado empresário, através de outros elementos da rede, recruta e seleciona várias meninas (conhecidas como meninas de programa no Brasil) e coloca-as numa casa, onde o valor cobrado por cada programa vai ao dono da casa e mensalmente elas recebem um valor mediante o rendimento individual. Pelo nível alto de analfabetismo e sob efeito de bebidas alcoólicas e outras drogas que consomem como estimulantes, algumas se arriscam a fazer sexo 
desprotegido, tornando-se assim propensas a contaminação pelas doenças de transmissão sexual, incluindo HIV-AIDS.

Moçambique e Brasil aderiram a convenção das Nações Unidas contra o crime organizado transnacional relativo a prevenção, repressão e punição de tráfico de pessoas, em especial mulheres e Crianças, a conhecida como protocolo de Palermo. Embora tenham aderido este protocolo, a sua aplicabilidade, ainda é muito deficitária devido à falta de recursos humanos qualificados e especializados nesta matéria, refere-se a juízes, procuradores inclusive policiais migratórios.

Em Moçambique tanto como no Brasil a prostituição autônoma não constitui crime, mas a sua exploração e a cafetinagem ou, por outras palavras, pune-se quem tirar proveito da prostituição alheia. Neste caso, em Moçambique com as mudanças trazidas pela lei $\mathrm{n}^{\circ}$ 35/2014 de dezembro de 2014, o código penal no seu artigo 198 sobre tráfico de pessoas, preconiza que;

Aquele que recrutar, transportar, acolher, fornecer ou receber uma pessoa, sob pretexto de emprego, formação, aprendizagem, para fins de prostituição, trabalho forçado, escravatura, servidão involuntária, por dívida será punido com pena de prisão maior de 16 a 20 anos (Código penal moçambicano, 2014, art.198) $)^{4}$.

Para o Código penal brasileiro, o tráfico de pessoas para fins de exploração sexual, vem preconizado no seu artigo 231-CP e diz que estes atos compreendem;

\begin{abstract}
Promover ou facilitar a entrada no território nacional de alguém que nele venha a exercer a prostituição ou outra forma de exploração sexual, ou saída de alguém que vá exerce-la no estrangeiro. E sua pena varia de 03 a 08 anos de reclusão. No seu $\S 1^{\circ}$ incorre na mesma pena aquele que agenciar, aliciar, comprar a pessoa traficada, assim como, tendo conhecimento dessa condição, transporta-la, transferi-la ou aloja-la. $\$ 2^{\circ}$ a pena é aumentada da metade se: a) a vítima for menor de 18 anos, b) se a vítima não tem o necessário discernimento para a praticado ato e c) se o agente é ascendente, padrasto [...], ou empregador.
\end{abstract}

No Brasil, o código penal-CP, com as mudanças trazidas pelo dispositivo legal $\mathrm{n}^{\circ}$ 11.106, de 28 de março de 2005 e pela lei $n^{0} 12.015$ de 7 de agosto de 2009 , criminaliza o tráfico internacional e interno de homens e mulheres para fins de prostituição ou outra

\footnotetext{
4 http://www.wlsa.org.mz/wpcontent/uploads/2014/11/Lei35_2014Codigo_Penal.pdf. Acesso em: 04 ago.
} 2017. 
forma de exploração sexual. Por exemplo, o artigo 229 do Código Penal brasileiro preconiza que;

Manter, por conta própria ou de terceiros, estabelecimento em que ocorra exploração sexual, haja, ou não, intuito de lucro ou mediação direta do proprietário ou gerente: Pena - reclusão, de 2 (dois) a 5 (cinco) anos, e multa correspondente (Código Penal Brasileiro, 2015, art 229) ${ }^{5}$.

No seu artigo 230 preconiza que "Tirar proveito da prostituição alheia, participando diretamente de seus lucros ou fazendo-se sustentar, no todo ou em parte, por quem a exerça, a Pena de reclusão é de 1 (um) a 4 (quatro) anos, e multa correspondente".

Conforme uma organização não governamental Save the Children (2009), em Moçambique, as raparigas de 14-25 anos de idade são transportadas dos seus locais de proveniência para África do Sul pelos membros da rede e chegado a fronteira são facilitados a entrada para África do Sul por indivíduos designados localmente por mareyane que as facilitam a travessia ilegal em troca de dinheiro, podendo ser a pé ou de taxis locais sob cúmplice ou sob olhar desatenta das autoridades fronteiriças.

A fragilidade dasfronteiras com vários países e o alto índice de corrupção das autoridades de administração da justiça em controlar e punir os infratores, constitui um fator preponderante para a movimentação das mulheres em Moçambique, propiciando desta feita um clima fértil para a ocorrência de tráfico. Ao fato alia-se o analfabetismo, a desestruturação familiar e a própria pobreza que de certa forma torna vulnerável essa camada social.

De forma genérica são tidas como principais causas do tráfico de pessoas, mormente mulheres:

a) Pobreza ou vulnerabilidade sócio econômica das vítimas, no sentido de que as pessoas nesta situação facilmente se submetem as propostas de uma vida melhor sem questionar a veracidade das mesmas, simplesmente buscam satisfazer as suas necessidades de sobrevivência em razão da ausência de uma perspectiva do futuro risonho;

\footnotetext{
${ }^{5}$ Disponível em: http://www.amperj.org.br/store/legislacao/codigos/cp_DL2848.pdf.
} 
b) Demanda pela exploração sexual de mulheres, dado aos extraordinários lucros que atividade representa aos elementos da rede de traficantes.

c) Instabilidade Política, econômica e civil em regiões de conflito- no sentido de que as pessoas em particular as mulheres são obrigadas pela situação a aceitar qualquer proposta desde que consiga alcançar o seu único objetivo que é a sua sobrevivência.

d) Corrupção de funcionários públicos afetos nas fronteiras que aceitam suborno de traficantes para facilitar a travessia das mulheres traficadas.

e) Fragilidade na aplicação da lei- no sentido de que os agentes responsáveis pela aplicação da lei, não tem um domínio profundo da matéria em alusão por falta do preparo, neste caso, trata-se de policiais, procuradores e juízes, que muitas vezes absolvem criminosos alegadamente por falta de prova ou por meio de corrupção protagonizada pelos traficantes a estes agentes por forma amolecer o caso em investigação.

Conforme Dias (2005), o Brasil participa nas redes internacionais do tráfico de pessoas abaixo custo operacional, devido à existência de redes de comunicação, de bancos, casa de câmbios, aeroportos, portos e pelas facilidades de ingresso em vários países sem a formalidade de visto consular. Para ele, do levantamento feito pelo Ministério da Justiça, apurou-se que os Estados com maior índice deste problema de tráfico de mulheres para fins de exploração sexual são: Ceará, São Paulo, Rio de Janeiro e Goiás, respectivamente, em virtude de se tratarem de principais pontos de saída do país.

O Brasil é receptor de vítimas de tráfico. As vítimas saem principalmente de outros países como: Bolívia, Perú, África (Nigéria), China e Coreia. A maioria delas vive situações de uma autêntica violência, quer sexual, quer psicológica por parte dos seus traficantes. Toda a sua movimentação é vigiada e às vezes fazem se a rua na companhia de um membro da rede de traficante como um tradutor, mormente quando se trata de mulheres provenientes de países não falante do português. (DIAS, 2005). Sendo receptor, possui principais rotas de tráfico de pessoas em quase todas regiões do país (Sul, Sudeste, CentroOeste, Nordeste e Norte). Abaixo, a tabela das principais rotas nacionais e internacionais. 
Gráfico 1 - Localização de principais rotas de tráfico no Brasil

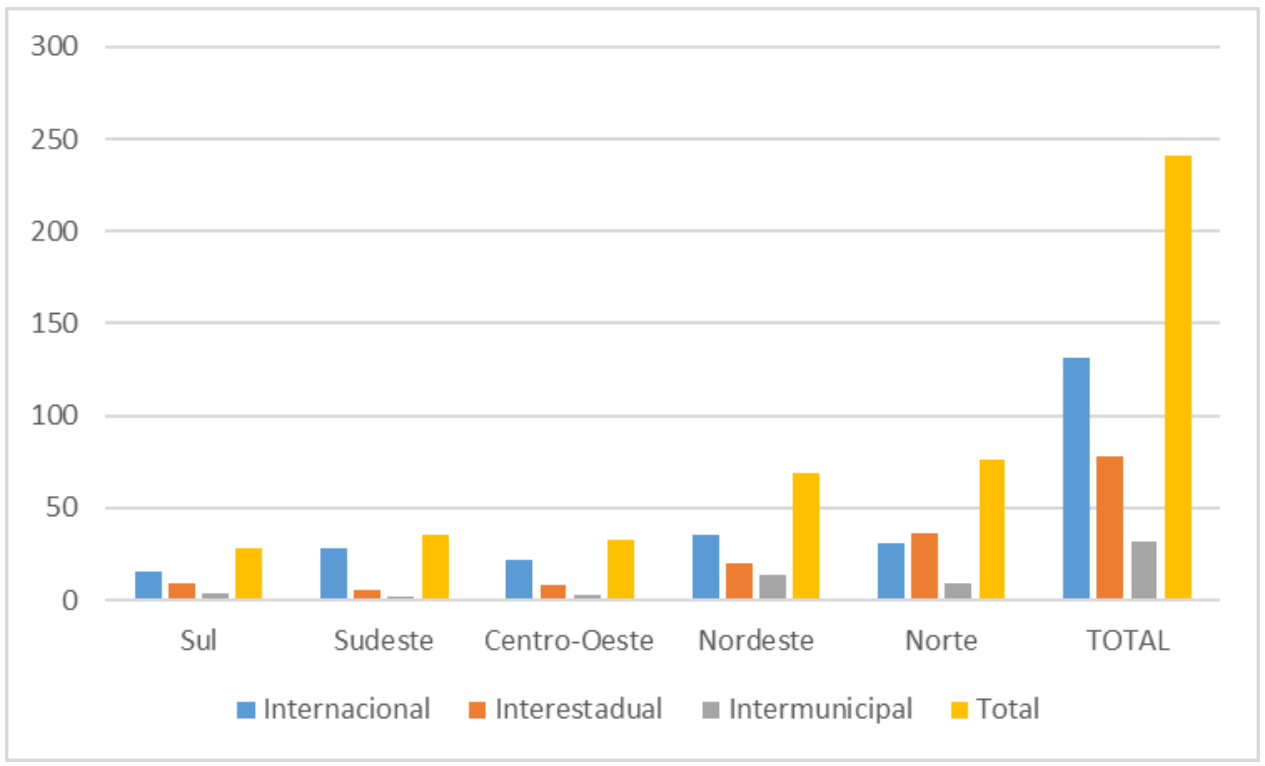

Fontes: Pesquisa de Mídia-Pestraf- Banco de Matérias Jornalisticas (2002)/Telatorios Regionais da Pestraf

Essas rotas são previamente organizadas estrategicamente, tendo em conta a fácil localização de rodoviárias, portos, aeroportos em fim, desde que sejam locais de fácil mobilidade das suas vítimas. Na maioria das vezes as pessoas traficadas saem do interior e dos Estados em direção a grandes centros urbanos ou diretamente para regiões de fronteiras internacionais (DIAS, 2005).

Conforme a PESTRAF (2002), as pessoas traficadas são mulheres, na sua maioria negras, de 15 -25 anos de idade, com um passado regado de violência doméstica e estupro, e na sua maioria a sua família igualmente apresenta sinais de violência social, interpessoal e até estrutural. Neste caso, essas mulheres vulneráveis são usadas como mercadoria pela classe burguesa e em troca recebe o salário que não coaduna com atividade realizada (MARX, 2013).

Em Moçambique, o tráfico de mulheres para fins de exploração sexual pode ocorrer a nível interno, neste caso, em casas alugadas para o efeito, em prostibulo, cabarés e bares, e a nível transnacional ocorre na vizinha África, dada a presença de industrias pornográficos modernizadas, sendo assim, a nível internacional as rotas para o tráfico no país são duas, uma no aeroporto internacional de mavalane e outra rota compreende a única rodovia que liga a parte norte, centro e Sul do país, terminando desta feita na 
fronteira com a África do Sul, pelo que havendo vontade política ${ }^{6}$ é possível estancar esta problemática social, através de uma aturada fiscalização de viajantes, sem no entanto recorrer ao dispêndio de recursos, quer humanos, quer materiais. Aliás, alguns prostíbulos ou casas alugadas por indivíduos (comerciantes) exclusivamente para a exploração sexual de mulheres são do conhecimento público, o que leva a crer que a falta da aplicação de dispositivos legais está por detrás da ocorrência sistemática de tráfico de mulheres.

De acordo com o relatório anual da Organização Internacional para a Migração (OIM) $\left(2011\right.$, p. 10) ${ }^{7}$, em África, as principais rotas de tráfico de pessoas compreendem os seguintes países: A rota Sul, através do Quénia, Tanzânia, Malawi e Moçambique ou outro país da "linha da frente" para a África do Sul. Em relação a esta rota, a metade dos Somalis e Etíopes que conseguem alcançar a África do Sul através desta rota continuam a viagem para os EUA, Europa e Austrália. Mas, cerca de 20000 indivíduos que seguem anualmente esta rota, muitos não conseguem sequer chegar a África do Sul por vários motivos, dentre os quais o seu resgate pela polícia ou pela morte.

Neste caso, inequivocamente pode se entender que o grande mercado de tráfico de pessoas em especial mulheres é a África do Sul, dada a sua elevada economia a nível da África e do mundo.

Segundo Louise Shelley (2010, p. 5):

O tráfico de pessoas está entre os crimes transnacionais mais crescentes, pois atual conjuntura global criou um aumento da demanda e da oferta deste mercado. Os fluxos migratórios são volumosos e este comércio ilegal está escondido na movimentação massiva de pessoas. A oferta existe, pois, a globalização causou maiores disparidades econômicas e demográficas entre o mundo desenvolvido e aquele em desenvolvimento, em paralelo com a feminização da pobreza e a marginalização de várias comunidades rurais.

Os mandantes do tráfico de pessoas representam "atores invisíveis", que comandam redes organizadas de tráfico de pessoas, sendo que o seu perfil sempre continua a ser, por muito tempo, uma incógnita. Isto explica-se pelo fato de que, até hoje, não há informação exaustiva de pessoas que tenham chegado ao destino final do tráfico

\footnotetext{
${ }^{6}$ Alguns prostíbulos geridos por gente burguesa são do conhecimento de toda gente inclusive das autoridades, dada a sua localização em locais públicos de diversão noturno, não se fazendo confundir com a prostituição autônoma.

${ }^{7}$ https://pt.slideshare.net/profjanaina/oim-organizao-internacional-para-migracao.
} 
de pessoas e que conseguiram depois contar a sua experiência. O mediatizado "Caso Diana" ${ }^{8}$ constitui um dos únicos casos, cujas vítimas chegaram ao destino final do tráfico, mas, mesmo assim, ainda não se tem com exatidão, informações sobre o perfil dos referidos mandantes. Trata-se de protagonistas cujas identidades são cuidadosamente encobertas, através de vários mecanismos de disfarce. Esta é uma característica que faz crer que os mandantes do tráfico de pessoas em Moçambique, operam numa complexa rede de crime organizado. Ademais, ainda que as vítimas tenham visto os mandantes, estes aparecem dissimulados de homens de negócios. E consequentemente, é difícil determinar com exatidão se os mandantes são moçambicanos ou estrangeiros, jovens ou adultos, do sexo masculino ou feminino, muito menos a extensão do seu poder (MAGODE, et al., 2014).

Segundo Jornal País (2010) ${ }^{9}$, o Departamento de Estado Norte Americano, no seu $10^{\circ}$ Relatório anual sobre o tráfico de pessoas, relativo ao ano de 2009, abarcando 117 países, acusa Moçambique de não cumprir com os padrões mínimos exigidos para a eliminação do tráfico e, fala-se, igualmente, de subornos perpetrados pelos traficantes a oficiais governamentais para permitirem o movimento das vítimas de tráfico no país e além-fronteiras. Ainda conforme a fonte, Moçambique é tido como um país de origem e também de destino, embora a um nível reduzido, de tráfico de pessoas, especificamente, para efeito de trabalhos forçados e prostituição forçada. O uso de trabalhadores infantis em atividades forçadas ou servidão por dívida constitui prática comum nas áreas rurais de Moçambique, muitas vezes, com a cumplicidade dos membros de família.

No mesmo documento, consta que mulheres e raparigas das áreas rurais são atraídas para as cidades com promessas de trabalho ou de educação, bem como para a África do Sul, para efeitos de servidão doméstica e prostituição forçada. As Organizações Não Governamentais têm reportado que as vítimas moçambicanas dos traficantes sexuais são levadas para "centros de formação" na Suazilândia e na África do Sul, em preparação da crescente demanda de prostituição em períodos de crescente turismo.

\footnotetext{
${ }^{8}$ Caso que mencionamos anteriormente.

9 http://opais.sapo.mz/index.php/sociedade/45-sociedade/6995-mocambique-e-um-dos-paises-de-origem-detrafico-de-seres-humanos-no-mundo.html. Acesso em: 05 ago. 2017.
} 


\section{ANÁLISE COMPARATIVA DOS DISPOSITIVOS LEGAIS DE COMBATE AO TRÁFICO DE MULHERES PARA FINS DE EXPLORAÇÃO SEXUAL ENTRE MOÇAMBIQUE E BRASIL}

Das análises feitas constatou-se que Moçambique tanto como Brasil possui dispositivos legais nacionais e internacionais para a prevenção do tráfico de pessoas, em especial Mulheres e Crianças.Moçambique para além de ter adoptado a legislação Internacional (Protocolo de Palermo), igualmente aprovou um conjunto de dispositivos legais abrangente na prevenção e no combate ao tráfico de pessoas, nomeadamente:

- Código Penal;

- Lei no 10/2004, de 25 de agosto (Aprova a Lei da Família e revoga o Livro IV do Código Civil);

- Lei n o 2053, de 22 de março (Lei do Abandono da Família);

- Decreto n 417/71, de 29 de setembro (Aprova o Estatuto de Assistência jurisdicional aos Menores);

- Lei n o 4/2002, de 5 de fevereiro (Altera o artigo 45.o do Estatuto de Assistência Jurisdicional aos Menores);

- Decreto no 5/89, de 10 de abril (Introduz a Simplificação Processual Respeitante à Concessão da Adopção e da Tutela).

- Lei no6/2008, de 9 de junho (Lei de Prevenção e Combate ao Tráfico de Seres Humanos, Especialmente Mulheres e Crianças);

- Lei no7/2008, de 9 de junho, (aprova a lei de Promoção e Proteção dos Direitos das Crianças) - Lei nㅇ/2008, de 15 de julho, (Aprova a Lei da Organização Tutelar de Menores).;

- Resolução no 9/88, de 25 de agosto (Ratifica a Carta Africana dos Direitos Humanos);

- Declaração Universal dos Direitos do Homem;

- Organização Internacional do Trabalho, Convenção no 138, Idade Mínima de Admissão ao Emprego, Resolução nำ/2003, de 22 de abril, do Conselho de Ministros.

- Resolução n.o 43/2002, de 28 de maio (Concernente à Adesão ao Protocolo Facultativo à Convenção das Nações Unidas sobre os Direitos da Criança relativo à Venda de Crianças, Prostituição e Pornografia Infantil); 
- Resolução n. o 19/90, de 23 de outubro (Ratifica a Adesão à Convenção sobre os Direitos da Criança);

- Resolução n. o 20/98, de 26 de maio (Ratifica a Adesão à Carta Africana dos Direitos e Bem-Estar da Criança);

- Resolução no 4/93, de 2 de junho (Ratifica a Convenção sobre a Eliminação de Todas as Formas de Discriminação da Mulher);

- Organização Internacional do Trabalho, relativa à Interdição das Piores Formas de Trabalho das Crianças e à ação imediata com vista à sua eliminação, Resolução no 6/2003 de 23 abril, do Conselho de Ministros;

A título ilustrativo a lei no 6/2008, de 9 de junho, possui um conjunto de disposições legais que estão em conformidade com o Protocolo Adicional à Convenção das Nações Unidas contra a Criminalidade Organizada Transnacional relativo à Prevenção, à Repressão e à Punição do Tráfico de Pessoas, em especial de Mulheres e Crianças e ao mesmo tempo com a Carta Africana da Juventude. Ela constitui uma plataforma para o aprimoramento das medidas de punição e de desencorajamento de práticas contra a dignidade humana, em especial das Mulheres e das Crianças.

Por sua vez, Brasil para além do seu Código Penal, aderiuum conjunto de legislação Internacional de Proteção à Mulheres e Crianças, nomeadamente ${ }^{10}$ :

- Protocolo de emenda da convenção para a repressão do tráfico de Mulher e Criança1948 (Decreto n 37.176 de 15/04/1955);

- Convenção e Protocolo final para Repressão do Tráfico de Pessoas e do Lenocínio -1958 (Decreto ${ }^{\circ} 46.981$ de 8/10/1959;

- Convenção da Organização Internacional do Trabalho (OIT) n 100 sobre igualdade de Remuneração -1957 (Decreto nº 62.150 de 19/01/1968);

- Convenção Sobre a Eliminação de todas as formas de Discriminação Contra Mulher-1984 (Decreto $n^{\circ} 4.377$ de 13/09/2002);

- Convenção Relativa à proteção e a Cooperação Matéria de Adoção Internacional (Convenção de Haia) -1999 (Decreto nº 3.087 de 21/06/1999).

\footnotetext{
${ }^{10}$ http://www.justica.sp.gov.br/StaticFiles/SJDC/ArquivosComuns/ProgramasProjetos/NETP/trafico $\% 20 \mathrm{de} \% 20 \mathrm{p}$ essoas $\% 20$ para\%20fins\%20de\%20exploracao\%20sexual.pdf.
} 
- Convenção Internacional para Prevenir, Punir e Erradicar a Violência Contra a Mulher (Convenção de Belém do Pará) -1995 (Decreto nº 1973 de 1/06/1996).

- Convenção Internacional Sobre Trafico Internacional de Menores-1997 (Decreto n 2.740 de 20/08/1998);

- Protocolo Facultativo da Convenção Sobre a Eliminação de todas as formas de Discriminação Contra Mulher -2002 (Decreto n 4.316 de 30/07/2002);

- Convenção da OIT $\mathrm{n}^{\circ} 182$ Sobre as piores formas de Trabalho Infantil-2000 (Decreto $\mathrm{n}^{\circ}$ 3.597 de 12/09/2000;

- Convenção Contra o Crime Organizado Transnacional e Protocolo Adicional para a Prevenção, Repressão e Punição do Tráfico de Pessoas, Especialmente Mulheres e Criancas-2004 (Decreto $n^{\circ} 5.015$ e $n^{\circ} 5.017$ de 12/03/2004).

Não obstante a presença de um conjunto de dispositivos legais, a sua aplicabilidade em Moçambique tanto como no Brasil está aquém das expectativas do legislador, por um lado, por falta de preparação dos agentes responsáveis pela aplicação destes dispositivos legais, para além de ser difícil a produção de provas indiciárias dado que as provas incidem sobre as vítimas que raramente mostram abertura em colaborar com a justiça. Por outro lado, tem se a corrupção dos funcionários públicos responsáveis pela aplicação da lei, desde os policiais, juízes, procuradores até aos funcionários públicos afetos nas fronteiras, que recebem suborno dos traficantes, facilitando desta feita a impunidade e a travessia das vítimas de tráfico para além fronteira.

\section{CONSIDERAÇÕES FINAIS}

A vulnerabilidade do tráfico de pessoas em especial mulheres em Moçambique e no Brasil, incide sobre jovens que sentem no seu cotidiano a exclusão social e econômica.

Embora os Códigos Penais moçambicano e brasileiro preconizam uma pena mais severa aos casos ligados ao tráfico de mulheres para fins de exploração sexual, esses casos ocorrem sistematicamente, sem aplicabilidade destes dispositivos legais.

Em Moçambique observa-se que a falta de preparo das instituições de Administração da justiça e outras instituições privadas de prevenção e tratamento desses casos, concorre para a sua ocorrência de forma impune. Alia-se também a fragilidade no 
controle fronteiriço e sua vulnerabilidade ao suborno protagonizado por elementos da rede criminosa.

Em Moçambique e no Brasil, a prostituição autônoma não é passível de uma censura jurídica, mas sim, aos terceiros que se aproveitam do fruto da prostituição ou que propicia para que tal ocorra. Mas também se observou que em ambos os países, a impunidade dos casos confirmados de tráfico de mulheres para exploração sexual faz com que os seus transgressores aumentem mais investidas nestas atividades, dado ao seu maior poder de lucro.

Em Moçambique, o maior número de mulheres traficadas para África do Sul padece de doenças de transmissão sexual, incluindo HIV-HIDS, dada a sua vulnerabilidade em não usar o preservativo nas suas relações sexuais cotidianas e ocasionais.

\section{REFERÊNCIAS}

GAATW - Aliança Global Contra Tráfico de mulheres. Direitos Humanos e Tráfico de pessoas: Um manual. Rio de Janeiro: GAATW, 2006.

BIRKHANN, Gabriel. Visões clássicas: sociologia do Direito e sua importância no conhecimento jurídico. Pergaminho, v. 6, p. 24-38, 2015.

BRASIL. Código Penal, 1940. Redação dada pela lei $n^{\circ} 12.015$ de 2009 [online]. Disponível em: http://www.amperj.org.br/store/legislacao/codigos/cp_DL2848.pdf. Acesso em: 04 ago. 2017.

Convenção das Nações Unidas Contra o crime Organizado Internacional (Convenção de Palermo). Palermo, Itália, 2000.

Convenção da OIT $\mathrm{n}^{\circ} 182$ Sobre as piores formas de Trabalho Infantil-2000 (Decreto $\mathrm{n}^{\circ}$ 3.597 de 12/09/2000.

DIAS, Cláudio Sérvulo da Cunha. Tráfico de pessoas para fins de exploração sexual. 1. Ed. Brasília: OIT, 2005 [online]. Disponível em: http://www.justica.sp.gov.br/StaticFiles/SJDC/ArquivosComuns/ProgramasProjetos/NETP/ trafico\%20de\%20pessoas\%20para\%20fins\%20de\%20exploracao\%20sexual.pdf. Acesso em: 05 ago. 2017.

IBGE. Síntese de indicadores sociais: Uma análise das condições de vida da população brasileira. 2015. Disponível em: https://biblioteca.ibge.gov.br/visualizacao /livros/liv95011.pdf. Acesso em: 29 jan. 2019. 
INSTITUTO NACIONAL DE ESTATísTICA-MOÇAMBIQUE. (2010). Projeções anuais da População total urbana e rural, Maputo (2007-2040). Editora do INE. Maputo.

INSTITUTO NACIONAL DE ESTATÍSTICA-MOÇAMBIQUE. Resultados definitivos referentes ao recenseamento da população e habitação de 2017. Maputo, 2017

JOARNAL PAÍS. Moçambique é um dos países de origem de tráfico de seres humanos no mundo, 2010 [online]. Disponível em: http://opais.sapo.mz/index.php/sociedade/45sociedade/6995-mocambique-e-um-dos-paises-de-origem-de-trafico-de-seres-humanosno-mundo.html. Acesso em: 05 ago. 2017.

JORNAL VERDADE. Justiça Sul-africana Condena Diana a prisão perpetua, Maputo, 21 jul. 2011 [online]. Disponível em: http://www.verdade.co.mz/nacional/21026-justi-ca-sulafricana-condena-diana-a-prisao-perpetua. Acesso em: 04 ago. 2017.

JORNAL VOA. Bento Kangamba envolvido no tráfico de mulheres brasileiras há uma década, Angola, 29 out. 2013 [online]. Disponível em: https://www.voaportugues.com/a/bento-kangamba-envolvido-no-trafico-de-mulheresbrasileiros-ha-uma-decada/1779355.htm. Acesso em: 04 ago. 2017.

PROTOCOLO DE PALERMO, 2000 [online]. Disponivel em: http://sinus.org.br/2014/wpcontent/uploads/2013/11/OIT-Protocolo-de-Palermo.pdf. Acesso em: 05 ago. 2017.

LEAL, Maria Lúcia; LEAL, Maria de Fátima P. (org). Pesquisa sobre tráfico de mulheres, crianças e adolescentes para fins de exploração sexual comercial PESTRAF: relatório nacional-Brasil. Brasília: CECRIA, 2002 [online]. Disponível em: http://www.childhood.org.br/wp-content/uploads/2014/03/Pestraf_2002.pdf. Acesso em: 05 ago. 2017.

Lei $n^{0}$ 35/2014. Revisão do Código Penal moçambicano, de 31 de dezembro de 2014 [online]. Disponível em: http://www.wlsa.org.mz/wp-content/uploads/2014/11/Lei35_2014Codigo_Penal.pdf. Acesso em: 04 ago. 2017.

MARIANO, Esmeralda; BRAGA, Carla; MOREIRA, André. Estudo sobre o tráfico de órgãos e partes do corpo Humano na Região Sul de Moçambique. Maputo: CEMIRDE, 2016.

MARX, Karl. O capital. Crítica da Economia Política. [s.l.]: Goitempo, 2013. [online]. Disponível em: https://coletivocontracorrente.files.wordpress.com/2013/10/ tmpsq7jbv.pdf. Acesso em: 03 de ago. 2017.

MONTEIRO, C; OSORIO, C. Tráfico de Mulheres e Criança. Maputo: WLSA Mozambique, 2009.

ORGANIZACAO INTERNACIONAL PARA MIGRACAO, 2011 [online]. Disponível em: https://pt.slideshare.net/profjanaina/oim-organizao-internacional-para-migracao. Acesso em: 05 ago. 2017.

SAVE THE CHILDREN. The Internal Trafficking and Exploitation of Women and Children in Mozambique. Save the Children Mozambique, 2009

SHELLEY, Louise. Human Trafficking. A Global Perspective. New York: Cambridge University Press, 2010 [online]. Disponível em: http://www.globalitygmu.net/archives/3271. Acesso em: 05 ago. 2017. 
UNESCO. Tráfico de Pessoas em Moçambique: Causas principais e Recomendações. Policy Paper No $\quad 14.1 \quad[P], \quad 2006 \quad$ [online]. Disponível em: http://unesdoc.unesco.org/images/0014/001478/147846por.pdf. Acesso em: 05 ago. 2017.

WISKSTROM, P; TREIBER, K. Violence as situational action. ICJV, v. 3, n. 1, p.75-96, 2009.

MALOA, Joaquim Miranda; FRANZE, José Joaquim. Tráfico de mulheres para fins de exploração sexual: uma análise comparativa entre Moçambique e Brasil. RBSD - Revista Brasileira de Sociologia do Direito, v. 6, n. 2, p. 144-161, maio/ago. 2019.

Recebido em: 01/01/2019

Aprovado em: 21/03/2019 